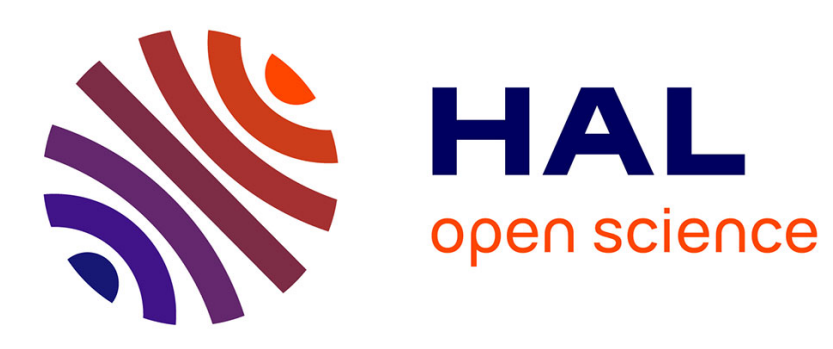

\title{
Interfacial Tension Measurement with an Optofluidic Sensor
}

\author{
Nam-Trung Nguyen, Sumantri Lassemono, Franck Chollet, Chun Yang
}

\section{To cite this version:}

Nam-Trung Nguyen, Sumantri Lassemono, Franck Chollet, Chun Yang. Interfacial Tension Measurement with an Optofluidic Sensor. IEEE Sensors Journal, 2007, 7 (5), pp.692-697. 10.1016/j.optlaseng.2008.05.008 . hal-00340424

\section{HAL Id: hal-00340424 https://hal.science/hal-00340424}

Submitted on 21 Nov 2008

HAL is a multi-disciplinary open access archive for the deposit and dissemination of scientific research documents, whether they are published or not. The documents may come from teaching and research institutions in France or abroad, or from public or private research centers.
L'archive ouverte pluridisciplinaire HAL, est destinée au dépôt et à la diffusion de documents scientifiques de niveau recherche, publiés ou non, émanant des établissements d'enseignement et de recherche français ou étrangers, des laboratoires publics ou privés. 


\title{
Interfacial Tension Measurement with an Optofluidic Sensor
}

\author{
Nam-Trung Nguyen, Sumantri Lassemono, Franck Alexis Chollet and Chun Yang
}

\begin{abstract}
This paper reports a novel optofluidic sensor for measuring dynamic interfacial tensions. The field of micro optofluidics utilizes both microfluidic and microoptic technologies. Thus, our sensor consists of a mirofluidic network and an optical detection system. The sensor is able to measure both surface tension or liquid/liquid interfacial tension. In the case of surface tension measurement, the liquid sample is introduced into a main channel, while air is injected through a T-junction. In the case of liquid/liquid interfacial tension measurement, a second immiscible liquid such as oil is introduced into a main channel, while the sample liquid is injected through the T-junction. The formation frequency of the micro bubbles or micro droplets represent the interfacial tension between the two phases. This frequency can be measured easily by optical detection. Measurements were carried out for aqueous solutions with different concentrations of the ionic surfactant CTAB (Cetyl Trimethyl Ammonium Bromide). The actual interfacial tensions of these solutions were calibrated with a commercial tensiometer (FTA200, First Ten Angstrom). The measurement results show a clear relation between the interfacial tension and the formation frequency. Furthermore, our sensor can be used to identify the critical micelle concentration (CMC) of a surfactant. The sensor potentially allows the use of a minute amount of sample compared to the relatively large amount required for existing commercial systems.
\end{abstract}

Index Terms- micro optofluidics, microfluidics, interfacial tension, lab on a chip.

\section{INTRODUCTION}

Interfacial tension between two immiscible liquids or the surface of an aqueous solution are important parameters in many industrial and domestic applications. Interfacial tension and surface tension depend on the surfactant concentration in the solution. Up to a certain concentration, surface tension is inversely proportional to the surfactant concentration. Above this concentration, surfactant molecules start to cluster and form micelles, surface tension remains almost constant. This critical concentration is called the critical micelle concentration (CMC). A low-cost sensor for measuring the CMC of detergent in automatic washing machines would allow the feedback signal for automatic detergent dispensing, which would have a big impact on saving detergent cost and protecting the environment.

Existing measurement methods for interfacial tension can be categorized in five groups: direct measurement using microbalance, measurement of capillary pressure, analysis of capillary gravity forces, gravity distorted drop, reinforced distortion of

Manuscript received ...., 2006; revised ...., 2006.

N. T. Nguyen is with School of Mechanical and Production Engineering, Nanyang Technological University, 50 Nanyang Avenue, Singapore 639798. Email: mntnguyen@ntu.edu.sg drop [1]. All these techniques require a relatively large amount of sample and are only suitable for desktop instruments. Designing a handheld instrument for interfacial tension would be difficult with the above concepts.

Recently, a number of research groups focused on the formation of droplets and bubbles in microchannels and tried to use this process in microfluidics [2]. The formation of monodisperse droplets have traditional applications in the fields of food science, cosmetics, and pharmaceutics. The current focus for this phenomenon is its application in microreaction technology [3]. Most of the previous works are based on droplets formed between an aqueous sample and oil. The chaotic flow pattern can improve mixing inside a moving droplet significantly. Recent applications of monodisperse droplets include DNA analysis, protein crystallisation [4], analysis of human physiological fluids, encapsulation [5], and production of polymeric micro beads [6]. Uniform droplets can be prepared using a simple T-junction [7] or a cross junction [8]. To our best knowledge, no previous works used the formation of monodisperse droplets and bubbles for measuring the surface tension of an aqueous liquid and the interfacial tension between the two immiscible liquids. Furthermore, the generation of micro bubbles in a gas/liquid system was not mentioned in the recent reported works. Olthuis et al. [9] reported microbubble generation based on electrolysis. Bubble formation was detected electrically. This method was limited by aqueous sample, and gas/liquid interfacial tension. The reported results show a bad reproducibility of bubble formation due to the large numbers of bubbles evolving at the same time from the electrode surface. Bubble formation relies entirely on the balance between surface tension and buoyancy force. In micro scale, surface tension is dominant while volume-based buoyancy force becomes negligible. Thus, further miniaturization is not suitable for this concept.

Our paper presents a micro optofluidic sensor for interfacial tension measurement. The device generates and detects air bubbles in a sample flow. Our sensor prototype was fabricated on a polymethyl methacrylate (PMMA) substrate by laser machining and direct thermal bonding. Air bubbles were formed at a T-junction between a carrier channel for the sample liquid and a smaller injection channel for air. Experimental results showed that the $\mathrm{T}$-configuration allows reliable and reproducible generation of air bubbles in the measured liquid sample. The generated air bubbles are detected optically downstream using a pair of optical fibres. The optical fibres are placed oppositely across the main flow channel. One is guiding laser light into the channel, the other one is for detecting the bubble signal. The experimental data shows a 


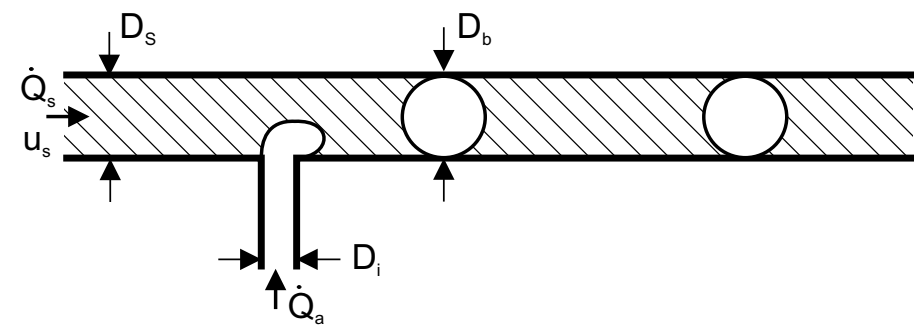

Fig. 1. A simple model of bubble formation.

clear relation between the surface tension and the formation frequency of the bubbles, which can be easily determined from the output signal of the optical detection system. Following, we first discuss a simple analytical model for the relations between surface tension and the formation frequency of the bubbles. The model also helps to identify other parameters of the sample liquid, which may affect the bubble formation frequency besides surface tension. Next, the paper describes the fabrication process and experimental characterization of the sensor. The actual surface tension values were calibrated using a commercial tensiometer.

\section{THEORY}

Figure 1 depicts a simple model of bubble formation. Since a complex model including the formation of air plug is very difficult to formulate, this model only serves the purpose of understanding the relations between key parameters such as bubble size, formation frequency, sample flow rate, and most importantly the surface tension. This model assumes a fixed flow rate ratio between air and sample liquid $\left(\alpha=\dot{Q}_{\mathrm{a}} / \dot{Q}_{\mathrm{s}}\right)$. Further assumptions are small bubbles size $(\alpha \ll 1)$ and incompressibility of air. Since bubbles in the model are formed in micro scale and the flows are in steady state, mass related forces such as inertial force, momentum force and buoyancy force are neglected.

As the air bubble grows in the liquid flow, the surfactant concentration at the bubble surface is not uniformly distributed. The presence of the surface tension gradient around the bubble leads to a possible Marangoni force acting on the bubble. If the surfactant solution is dilute, the Marangoni force is assumed to be negligible, and thus the force balance equation only includes the drag force of the sample flow and the interfacial tension at the injection port:

$$
\begin{aligned}
& F_{\text {drag }}=F_{\text {surfacetension }} \\
& \frac{1}{2} C_{\mathrm{d}} \rho u_{\mathrm{s}}^{2} A_{\mathrm{d}}=C_{\mathrm{s}} \pi D_{\mathrm{i}} \sigma
\end{aligned}
$$

where $u_{\mathrm{s}}, A_{\mathrm{d}}, D_{\mathrm{i}}$, and $\sigma$ are the average velocity of the sample flow, the effective drag surface, the diameter of the injection opening, and the surface tension, respectively. In addition, $C_{\mathrm{d}}$ and $C_{\mathrm{s}}$ are the drag coefficient and the coefficient for the surface tension. The drag coefficient of a sphere at a low Reynolds number Re is calculated as $C_{\mathrm{d}}=24 / \mathrm{Re}$. The coefficient $C_{\mathrm{s}}$ depends on the contact angle and the shape of the injection port and is assumed here to be constant. The effective drag surface $A_{\mathrm{d}}$ grows with the bubble. If the bubble is a sphere, the effective drag surface at the detachment moment is:

$$
A_{\mathrm{d}}=\frac{\pi D_{\mathrm{b}}^{2}}{2}
$$

where $D_{\mathrm{b}}$ is the diameter of the bubble as depicted in Fig. 1 . Initially the bubble is small, the surface tension is large enough to keep the bubble at the injection port. At the detachment moment, due to the continuous bubble growth the drag force is large enough to release the bubble. Substituting (2) into (1) results in the bubble diameter:

$$
D_{\mathrm{b}}=2 \sqrt{\frac{C_{\mathrm{s}}}{C_{\mathrm{d}}} d_{\mathrm{i}} \frac{\sigma}{\rho u_{\mathrm{s}}^{2}}}
$$

The formation frequency can be estimated from the air flow rate $\dot{Q}_{\mathrm{a}}$ and the bubble volume $V_{\mathrm{b}}$ as:

$$
f=\frac{\dot{Q}_{\mathrm{a}}}{V_{\mathrm{b}}}
$$

Using the bubble diameter and the relation $\dot{Q}_{\mathrm{a}}=\alpha \dot{Q}_{\mathrm{s}}$, the formation frequency in (4) can be expressed as:

$$
f=\frac{3 \alpha D_{\mathrm{s}}^{2}}{16\left(C_{\mathrm{s}} D_{\mathrm{i}} / C_{\mathrm{D}}\right)^{\frac{3}{2}}} \frac{\rho^{\frac{3}{2}} u_{\mathrm{s}}^{4}}{\sigma^{\frac{3}{2}}}
$$

According to (5), the surface tension can be measured based on the formation frequency $f$, if all other parameters are constant. The density of the liquid has the same impact on the formation frequency as the surface tension. Thus, this method is only suitable for solutions with constant density and varying surface tensions such as those of diluted surfactants. In these solutions, the density change usually is of 3 to 4 orders less than the surface tension change. Equation (5) also shows a nonlinear relation between the formation frequency and the average sample velocity $\left(f \propto u_{\mathrm{s}}^{4}\right.$ ) or sample flow rate $\left(f \propto \dot{Q}_{\mathrm{s}}^{4}\right)$.

Figure 2(a) shows this relation graphically. The characteristics of bubble formation frequency versus surface tension at different sample flow rates are depicted in Fig. 2(b). Furthermore, if the Marangoni force is considered in equation (1) when the surfactant concentration is high, there will be an additional term for such force in the numerator of (5), resulting in a higher frequency.

\section{SENSOR CONCEPT AND FABRICATION}

The sensor prototype contains a microchannel network for droplet formation and an optical system for bubble detection. The basic T-configuration of the microchannel network is depicted in Fig. 1. For the measurement, air enters through the small injection microchannel, while the sample liquid flows in the larger microchannel. Bubble formation occurs at the junction between the two microchannels. The bubble formation frequency can also be tailored by the choice of channel diameters $D_{\mathrm{i}}$ and $D_{\mathrm{s}}$ as clearly indicated in (5).

The generated bubbles are detected downstream the sample microchannel. In our sensor prototype, the air bubbles are detected optically. Laser light enters the microchannel through an optical fibre. After passing across the sample micro channel, the laser is received on the other side by a second optical 


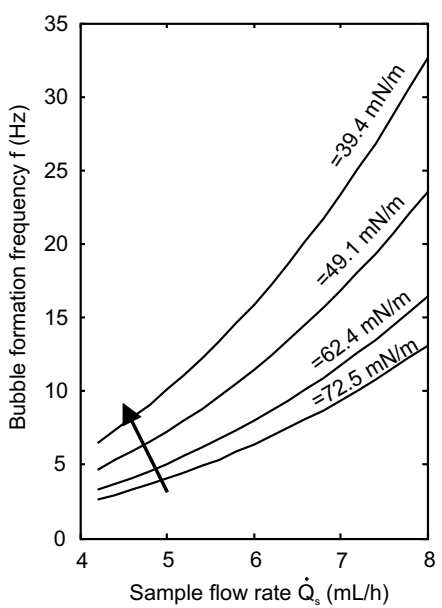

(a)

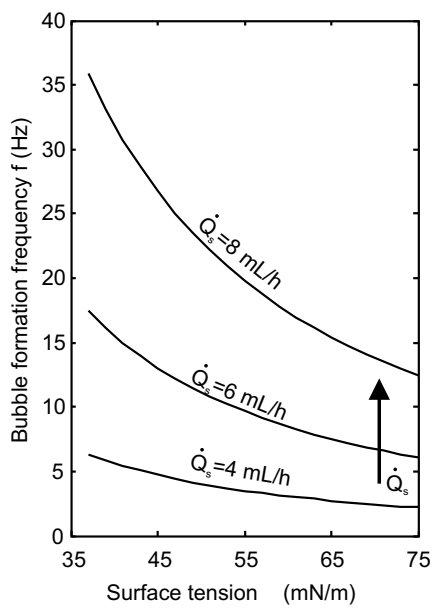

(b)
Fig. 2. Theoretical relations between the formation frequency and (a) the flow rate, (b) the surface tension.

fibre, which leads straight to an optical sensor. The passingby bubbles changes the intensity of the laser due to diffraction and absorption. Thus, the bubble can be well recorded as a pulse in the output signal of the optical sensor.

Sensor prototype was made of polymethyl methacrylate (PMMA). The microchannels were ablated into the substrate using $\mathrm{CO}_{2}$ laser, which has a relatively long characteristic wavelength of $10.6 \mu \mathrm{m}$. Therefore, the ablation profile is determined by thermal energy, which in turn has the same distribution as the laser intensity. The intensity of the laser beam has a Gaussian distribution, thus the cross section of the channel also has a Gaussian shape.

The Universal M-300 Laser Platform (Universal Laser Systems Inc.) was used for our machining purpose. This platform has a 25 Watt $\mathrm{CO}_{2}$ laser and a maximum beam speed of about $640 \mathrm{~mm} / \mathrm{s}$. The cross section of the engraved microchannel depends on the intensity distribution of the laser beam, its moving speed, the laser power and the thermal diffusivity of substrate material. The injection channel and the guides for inserting the optical fibres are both $175 \mu \mathrm{m}$ in width and 205 $\mu \mathrm{m}$ in depth. The larger microchannel for sample flow has a width of $340 \mu \mathrm{m}$ and a depth of $340 \mu \mathrm{m}$.

The guides for the two optical fibres are engraved at the end of the large microchannel. The optical fibres (AFS105/125Y, THORLABS Inc.) have a core diameter of $105 \mathrm{~m}$, a clad diameter of $125 \mathrm{~m}$, a buffer diameter of $250 \mathrm{~m}$, and a numerical aperture of 0.22 . Prior to the subsequent bonding process, the PMMA parts were carefully cleaned and rinsed in ethanol and DI-water. After positioning the fibres, the PMMA part with microchannels, optical fibres, and access holes is covered by a second PMMA part. The PMMA stack is then placed between a hotplate and a aluminium plate for direct thermal bonding. The bonding pressure can be adjusted by putting weights on top of the upper plate. After bonding at $165{ }^{\circ} \mathrm{C}$, the bonded stack is annealed at $80{ }^{\circ} \mathrm{C}$ for relieving stress. The bonding pressure was kept at about $20 \mathrm{kPa}$ [10]. Finally, stainless steel needles were glued to the access holes. The completed device is shown in Fig. 3. The same technology was previously used for making micropumps. Thus, the integration of micropumps into the sensor is possible [11].

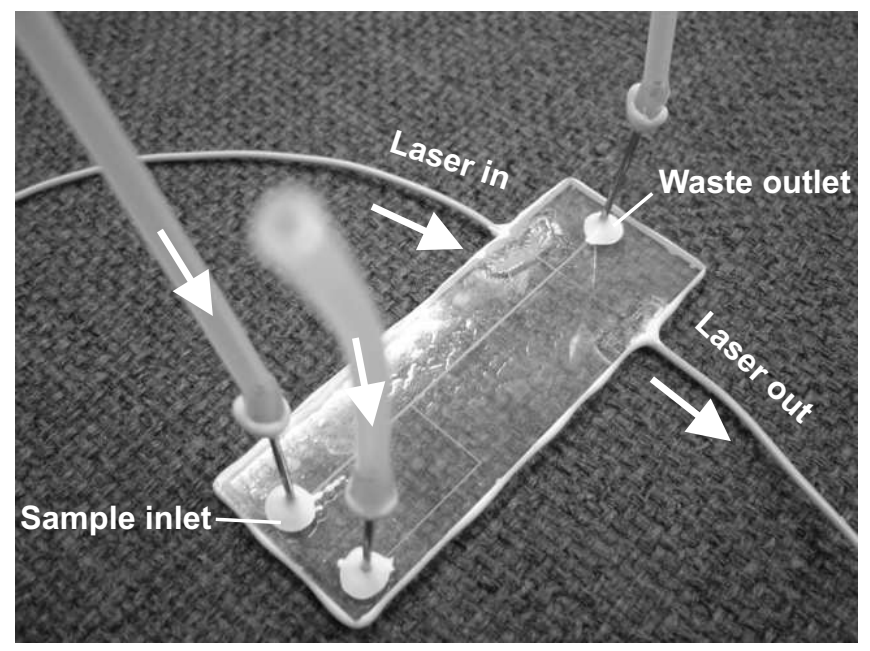

Fig. 3. The completed microfluidic sensor for dynamic surface tension measurement.

\section{EXPERIMENT}

In our experiments, a syringe filled with the sample liquid and an empty syringe (filled with air) are placed on a syringe pump (Cole-Parmer 74900-05). Both syringes are driven by the same stepper motor, we could make sure that the flow rate ratio was kept constant throughout the experiment. This flow rate ratio can be adjusted by choosing syringes with a corresponding ratio of cross sections. For the results presented in this paper, the volumetric flow rate ratio between air and sample liquid is kept at 1:4. Small flow rate ratios as assumed in the analytical model leads to relatively unstable droplet formation process.

For detecting the air bubbles, one optical fibre is positioned and aligned to a laser source (laser diode, $635 \mathrm{~nm}$ ), the other fibre is connected to an avalanche photodiode module (APD, C5460-01, Hamamatsu, Japan). The output signal from the APD is recorded by a digital oscilloscope (TDS220, Tektronix), which in turn is connected to a personal computer (PC) over a serial cable (RS232). Thus, the bubble signal can be recorded and analyzed later on the PC.

Cetyl trimethyl ammonium bromide (CTAB, $\mathrm{C}_{1} 9 \mathrm{H}_{42} \mathrm{BrN}$ ) was used as surfactant to vary surface tension values. Samples with different concentration ranging from $10^{-4} \mathrm{M}$ to $10^{-2} \mathrm{M}$ were tested. The surface tension of the samples were calibarated with a commercial tensiometer FTA200 (First Ten Angstrom). Table I summarises the measured surface tension values of these sample solutions. The data shows that surface tension decreases with increasing concentration. The CMC is about $10^{-3} \mathrm{M}$.

\section{RESUlTS AND DISCUSSIONS}

Figure 4 shows the typical bubble signals detected by the APD at a sample flow rate of $4 \mathrm{~mL} / \mathrm{h}$ for the different sample concentrations. The bubbles are represented by the pulses. The results here clearly show that the bubble becomes smaller and 
TABLE I

MEASURED SURFACE TENSIONS OF AQUeOUS SOlution OF CTAB.

\begin{tabular}{ll}
\hline Concentration $(\mathrm{M})$ & Surface tension $(\mathrm{mN} / \mathrm{m})$ \\
\hline 0 & 72.5 \\
$1 \times 10^{-4}$ & 62.4 \\
$5 \times 10^{-4}$ & 49.1 \\
$1 \times 10^{-3}$ & 39.4 \\
$5 \times 10^{-3}$ & 38.7 \\
$1 \times 10^{-2}$ & 38.6 \\
\hline
\end{tabular}

the formation frequency is higher with increasing surfactant concentration or decreasing surface tension. Beyond the CMC of about $1 \times 10^{-3} \mathrm{M}$, the formation process becomes unstable, the formation frequency fluctuates. This instability characteristic can be used to detect CMC. In the stable region up to $\mathrm{CMC}$, the pulse width ratio of 1:5 is consistent with the fixed flow rate ratio of 1:4 between air and sample liquid. Thus, the formation frequency also contains information about the pulse width or the bubble size. Following, only the formation frequency is evaluated and discussed.

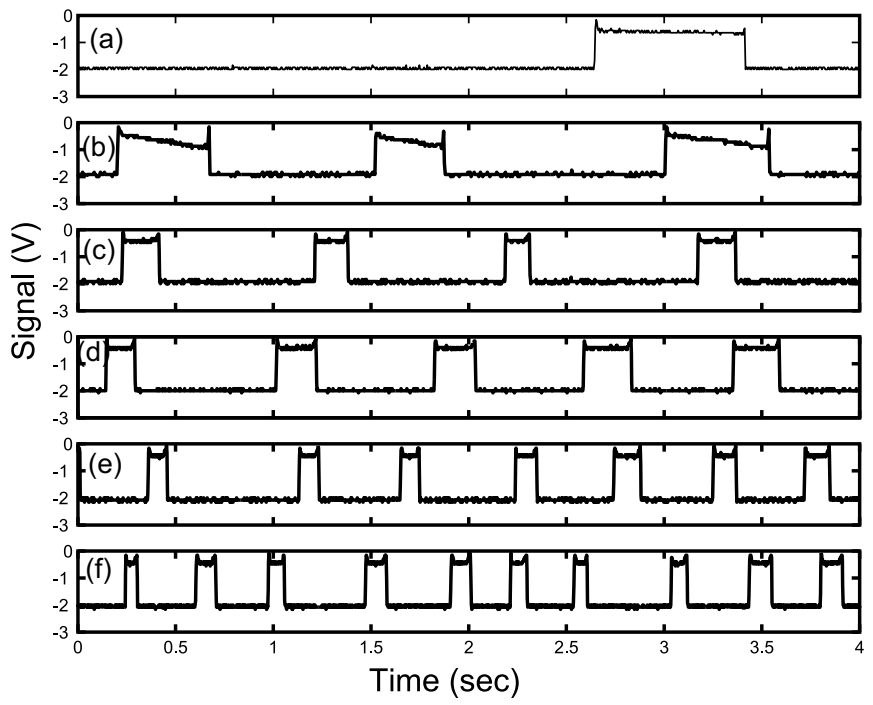

Fig. 4. Typical bubble signals detected by the APD at an air flow rate of 1 $\mathrm{ml} / \mathrm{h}$ (constant flow rate ratio $=1: 4$ ) and different surfactant concentrations: (a) $c=0 \mathrm{M}$, (b) $c=1 \times 10^{-4} \mathrm{M}$, (c) $c=5 \times 10^{-4} \mathrm{M}$, (d) $c=1 \times 10^{-3} \mathrm{M}$ (e) $c=5 \times 10^{-3} \mathrm{M}$, (f) $c=1 \times 10^{-2} \mathrm{M}$

Figure 5 depicts the measured frequency of bubble formation as a function of sample flow rate. From the theory, the expected non-linear relation can be observed clearly. The signal is stable and consistent at low sample flow rate and high surface tensions.

The characteristics of bubble formation frequency versus surfactant concentration are shown in Fig. 6. The results show that droplet formation frequency continues to increase beyond CMC. Since the surface tension does not change significantly at concentration higher than $\mathrm{CMC}$, the frequency increase could be caused by Marangoni force as indicated in the theoretical model.

Figure 7 shows the formation frequency as a function of surface tension. Surface tension values were calibrated according to the data listed in Table I. For diluted solutions with low surfactant concentrations, the curves agree well with

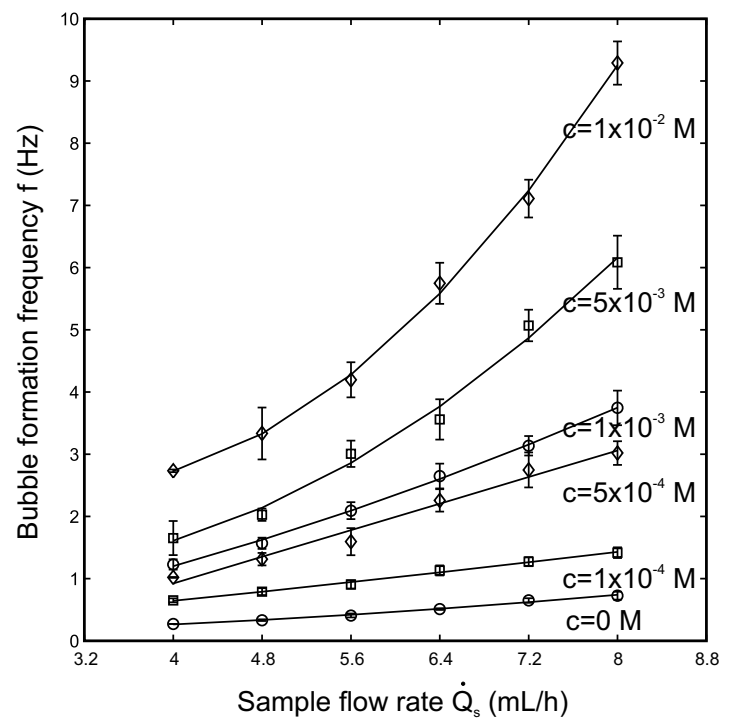

Fig. 5. Measured bubble formation frequency as function of surface tensions at air flow rates of $1 \mathrm{~mL} / \mathrm{h}$ and $2 \mathrm{~mL} / \mathrm{h}$.

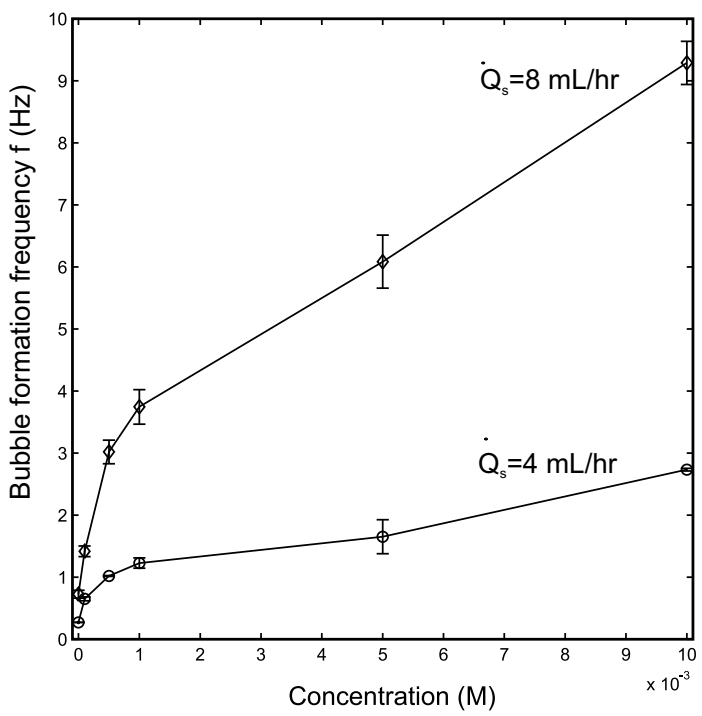

Fig. 6. Measured bubble formation frequency as function of surfactant concentration.

the general characteristics predicted by the theory and shown in Fig. 2(b). The abrupt change of the formation frequency at CMC can be clearly observed in Fig. 7. Up to CMC, bubble formation and detachment is dominated by the drag force, the formation frequency decreases almost linearly with increasing surface tension. In this range, formation frequency can be used directly for determining the surface tension. Beyond CMC, there is a sharp change in formation frequency. The Marangoni force caused by surface tension gradient on the bubble surface becomes dominant in this range and contributes to the increase of formation frequency.

\section{CONCLUSIONS}

In this paper, we presented a micro optofluidic sensor for interfacial tension measurement. The device has a microchannel network to form the air bubbles. The bubbles 


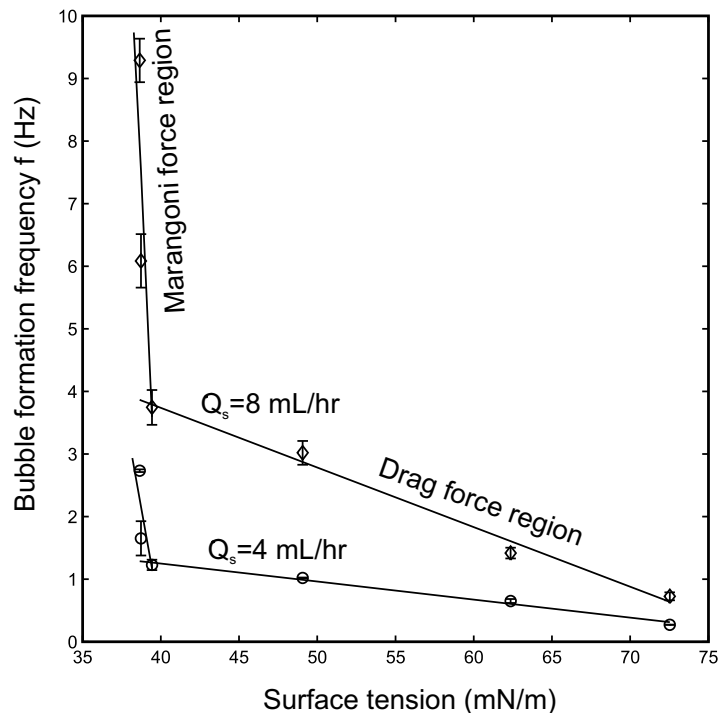

Fig. 7. Measured bubble formation frequency as function of surface tension.

were then detected optically. A bubble passing by the detection point diffracts a part of the incoming laser light. The change in intensity can be detected by the optical fibres placed on the other side of the channel. Due to the small changes in density, formation frequency depends only on the surfactant concentration or on the surface tension. Since the frequency increases monotonously with the concentration, bubble formation frequency can be related directly to the surfactant concentration. Up to CMC, the relation between surface tension and formation frequency is almost linear. Thus, formation frequency can be used to measure surface tension. Beyond CMC, the frequency changes sharply. Detecting the sharp changes may allow the sensor to determine this critical value of a surfactant solution.

\section{ACKNOWLEDGEMENTS}

This work was supported by the Academic Research Fund of the Ministry of Education Singapore, contract number RG22/05.

\section{REFERENCES}

[1] J. Drelich, C. Fang, and C. L. White, "Measurement of interfacial tension in fluid-fluid systems," in Encylopedia of Surface and Colloid Science. Marcel Dekker, 2002.

[2] T. Nisisako and T. T. T. Higuchi, "Droplet formation in a microchannel network," Lab on a Chip, vol. 2, pp. 24-26, 2002.

[3] M. R. Bringer, C. J. Gerdts, H. Song, J. D. Tice, and R. F. Ismagilov, "Microfluidic systems for chemical kinetics that rely on chaotic mixing in droplets," Phil. Trans. R. Soc. Lond. A, vol. 362, pp. 1087-1104, 2004.

[4] B. Zheng, J. D. Tice, and R. F. Ismagilov, "Formation of arrayed droplets by soft lithography and two-phase fluid flow and application in protein crystallization," Advanced Materials, vol. 125, pp. 1365-1368, 2004.

[5] S. Okushima, T. Nisisako, T. Torii, and T. Higuchi, "Controlled production of monodisperse double emulsions by two-step droplet breakup in microfluidic devices," Langmuir, vol. 20, pp. 9905-9908, 2004.

[6] T. Nisisako, T. Torii, and T. Higuchi, "Novel microreactors for functional polymer beads," Chemical Engineering Journal, vol. 101, pp. 23-29, 2004.

[7] Y. Thorsen, R. W. Roberts, F. H. Arnold, and S. R. Quake, "Dynamic pattern formation in a vesicle-generating microfluidic device," Physics Review Letters, vol. 86, pp. 4163-4166, 2001.
[8] R. Dreyfus, P. Tabeling, and H. Willaime, "Ordered and disordered patterns in two-phase flows in microchannels," Physics Review Letters, vol. 90, pp. 144505-144 507, 2001.

[9] W. Olthuis, A. Volanschi, and P. Bergveld, "Dynamic surface tension measured with integrated sensor-actuator using electrolytically generated bubbles," Sensors and Actuators B, vol. 49, pp. 126-131, 1998.

[10] Y. Sun, Y. C. Kwok, and N. T. Nguyen, "Low-pressure, high-temperature thermal bonding of polymeric microfluidic devices and their applications for electrophoretic separation," Journal of Micromechanics and Microengineering, vol. 16, pp. 1681-1688, 2006.

[11] T. Q. T. N. T. Nguyen, "A fully polymeric micropump with piezoelectric actuator," Sensors and Actuators B: Chemical, vol. 97, pp. 137-143, 2004.

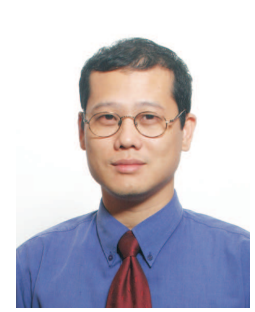

Nam-Trung Nguyen Nam-Trung Nguyen was born in Hanoi, Vietnam, in 1970. He received his Dip.Ing., Dr. Ing. and Dr. Ing. habil. degrees from Chemnitz University of Technology, Germany, in 1993, 1997 and 2004, respectively. Currently he is an Associate Professor with the School of Mechanical and Aerospace Engineering of the Nanyang Technological University in Singapore. His research is focused on microfluidics and instrumentation for biomedical applications. The second edition of his book "Fundamentals and Applications of Microfluidics" co-authored with S. Wereley will be published in summer 2006.

PLACE

PHOTO

HERE

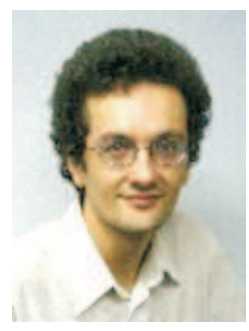

$\mathbf{S}$ umantri Lassemono was born in Indonesia, he is currently competing his undergraduate study at the School of Mechanical and Aerospace Engineering of the Nanyang Technological University in Singapore.

F ranck Alexis Chollet received his Electronics Engineering degree from the ENSERB, Bordeaux, France in 1991, and his Doctorate degree in Sciences Pour IIngénieur from the Université de FrancheComte, Besançon, France, in 1995. Currently, he is Associate Professor in the school of Mechanical and Aerospace Engineering at Nanyang Technological University, Singapore, and is the Vice-Director of the MicroMachines Centre.

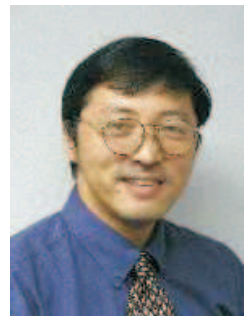

C hun Yang received the B.S. degree from the Department of Thermal Engineering of Tsinghua University (Beijing), M.S. degree in Thermophysics from University of Science and Technology of China (Hefei), and Ph.D. degree in Mechanical Engineering from University of Alberta (Edmonton). In 1999, I joined the Nanyang Technological University and is currently an Associate Professor. 